International Journal of Health Sciences
Available online at http://sciencescholar.us/journal/index.php/ijhs
Vol. 3 No. 3, December 2019, pages: 1 7
e-ISSN: 2550-696X, p-ISSN: 2550-6978
https://doi.org/10.29332/ijhs.v3n3.333

\title{
Dyslexia as Learning Problem and Its Pedagogical Intervention
}

\author{
CrossMark \\ José Lucas Delgado a, Yolanda Inés España Bone b, Maholy Antonella García Lascano c, \\ Saskia Giorlet García España d
}

Article history: Received 09 May 2019, Accepted: 31 August 2019, Published: 03 September 2019

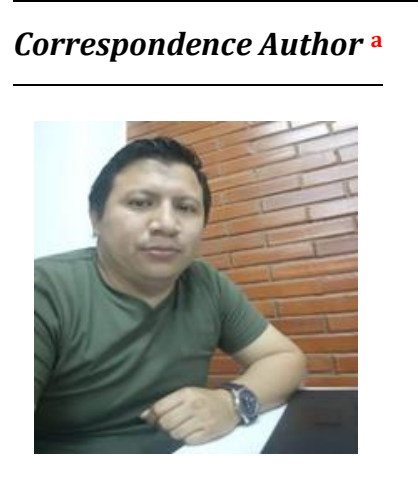

Keywords

difficulty;

dyslexia;

learning;

reading disorder;

teachers;

\begin{abstract}
The purpose of this work is to analyze the learning disorder known as dyslexia, which influences the teaching-learning process of both reading and writing. This difficulty has detected in the first years of his school stage at the time the child undertakes his first steps of reading, omitting or replacing some syllables with others; It has also reflected in writing since learning has not fully assimilated and is carried out with great difficulty. Given this, it is necessary for teachers to adopt measures or strategies that help to reduce this disorder, always relying on the diagnoses and guides of the specialists.
\end{abstract}

e-ISSN: 2550-696X, p-ISSN: 2550-6978 ${ }^{\circ}$ Copyright 2019. The Author. SS Journals Published by Universidad Técnica de Manabí. This is an open-access article under the CC BY-SA 4.0 license (https://creativecommons.org/licenses/by-sa/4.0/) All rights reserved.

\section{Contents}

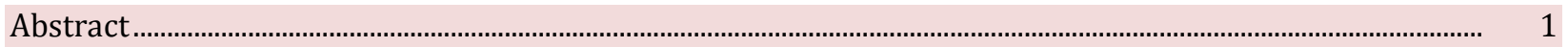

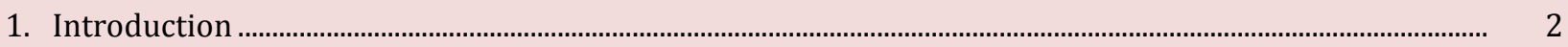

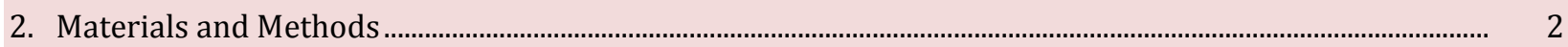

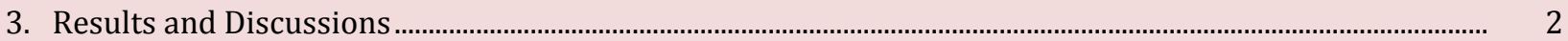

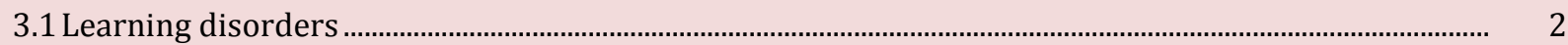

3.2 Learning problems ………………………………………………………………………………………….....

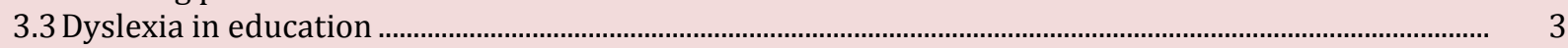

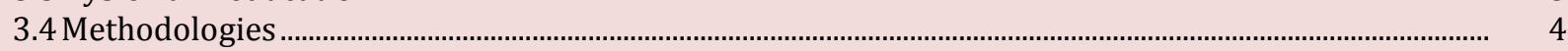

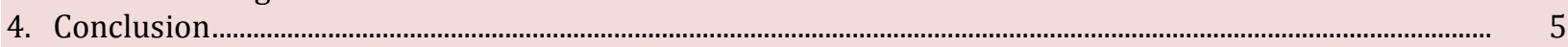

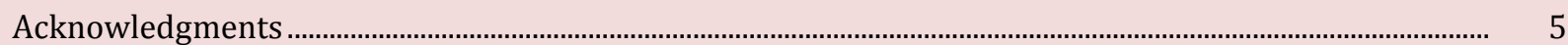

a Pontificia Universidad Católica del Ecuador, Portoviejo, Ecuador

b Pontificia Universidad Católica del Ecuador, Portoviejo, Ecuador

c Pontificia Universidad Católica del Ecuador, Portoviejo, Ecuador

d Pontificia Universidad Católica del Ecuador, Portoviejo, Ecuador 


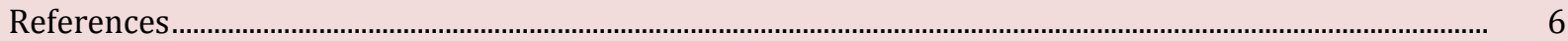

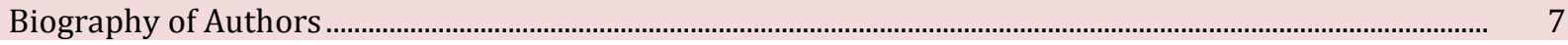

\section{Introduction}

Those who carry out the work of teachers should know about the different disorders that children present in their school stage, characteristics and application of different methodologies, emphasizing that these types of conditions should be treated as soon as possible avoiding thus falling into a depressive state, considering itself different from the other children.

Dyslexia is a learning disorder reflected in persistent reading and writing, which occurs in children and creeps into adolescence and adulthood (Malaga, 2014). This disorder has become very common although it has always been present among us derived as an alteration in neuronal development.

The human being uses his brain as a fundamental part for learning since since we are born until our brain dies he acquires knowledge permanently, the same that when suffering some type of disorder either hereditary or in the course of our life directly affects and Indirect to our learning for this reason is that an investigation is carried out to learn a little more about the different disorders that affect our learning even more in the process of reading and writing, for that we have made use of the concepts that different authors employ about these conditions, and how to use different teaching methodologies to meet this condition that affects a large part of human beings.

Dyslexia is an alteration of cognitive procedures, it is not compatible with the educational system, since this is based on the written code, hindering the teaching-learning process, in terms of assimilation of knowledge and attention.

\section{Materials and Methods}

The study and research carried out in the present work was carried out based on the inductive and deductive method, which allowed to enhance the logical analysis of the concepts related to learning disorders and the disadvantages that are present in the school stage, evidencing in certain alternatives for the application of new methodologies or learning strategies implemented in the respondents who suffer from this disorder.

It is necessary to emphasize that, all the adaptations made must be guided by professionals in the field. Its main objective is to look for alternatives to improve the learning process with the child from his / her school stage, both for the teacher and for the parents, who must work together for the welfare of the affected student.

In addition to the method outlined above, the literature review of documents between 2010 and 2017, written by different researchers who contribute their ideas in the study of learning disorders, was carried out.

\section{Results and Discussions}

\subsection{Learning disorders}

Learning disorders every day become more common in children, for this reason, both the teacher and the parent must be familiar with these types of disorders, the most common cases are dyslexia, dysgraphia, dyscalculia, both related to A problem in reading and writing. This problem is very silent, sometimes due to ignorance of these disorders teachers and parents believe that the child does it on purpose using methods not appropriate for correction.

Dyslexia is a disorder that mainly affects the ability to read and write, thus generating difficulties in the aspect of language, as an essential part of learning that is affected in the processing of information creating a gap between skills and abilities, having as a very important factor age, academic performance. Castejón et al., (2011), for this reason when we find children with problems in their writing, the teacher as the parent should pay close attention, since being a silent disorder can go unnoticed. 
Specific disorders of the development of school learning

a) Specific disorders of reading

b) Specific disorders of spelling

c) Specific disorders of calculation

d) Mixed disorders of the development of school learning

e) Other of the development of school learning

Source: Modified ICD-10, International Classification of Diseases

\subsection{Learning problems}

It is a condition that makes it difficult for people to develop their reading and writing skills, creating difficulties in children and adolescents in the social, emotional or behavioral fields, since sometimes people who suffer from this condition they are subject to teasing, rejection, the same that affect their emotional part, based on some studies carried out by experts, dyslexia varies between $5 \%, 10 \%$, and $17 \%$, it is considered by a tiny group of teachers who are not trained to attend this type of disorders the same that associate it with the bad conduct and academic leisure.

Dyslexia is a learning disorder that is directly coded with language (Ana et al., 2017; Vasquez et al., 2019; Delgado et al., 2019). They believe that this phenomenon is due to the lack of awareness of dyslexia by the educational community, especially by teachers; for an inadequate educational and legal framework to meet the educational needs detected in this student body, and for lack of regular use of a variety of multimodal resources; which is why it implies that both the authorities and the teachers take this type of disorders into account when evaluating the student, since due to their lack of knowledge there is no relevant curricular adaptation

\subsection{Dyslexia in education}

Dyslexia is a learning disorder caused by the alteration of the brain specifically the drill bit area that is responsible for controlling language and that persists throughout life, (Ortíz, 2016). Children between the ages of 5 and 7 are the most affected of this disorder, especially boys, the intensity of the disorder varies according to the age of the child, affecting functions related to motor areas and speech.

Students who are detected with this disorder must have a different teaching process so as not to be harmed academically, for this the teacher must search and use different techniques that facilitate the learning process. This type of disorder implies that the students have a greater degree of difficulty at the time of being evaluated since when reading the questions they can confuse with concepts of the same, before the exposed thing, the teacher will have to take into account strategies that can be implemented.

For their part, educational institutions must implement training plans so that teachers are more familiar with these types of disorders that have been and will be present in educational processes, always taking into account that, no child should be excluded for having this type of conditions, much less to be mocked, but rather to be helped and understood throughout their teaching-learning process.

Dyslexia is sometimes confused with a visual problem, or also called as a disability, but it should be emphasized that this disorder does affect learning, but it does not become a disability for the child since the child can fulfill the same activities of Normally, it is more in some studies conducted children with this problem are equal or more intelligent than children who do not present any learning conditions or problems.

One of the difficulties that people with dyslexia disorder present most is due to the recognition of words despite having all their sensory abilities intact, (Pennintong, 2012). He states that, because this disorder makes it difficult to read a text, for this reason, his learning process will be affected to such an extent that if it is not detected in time, the necessary emotional and professional help cannot be provided.

Dyslexic students respond best when using appropriate techniques when learning foreign languages, (Cervantes, 2013; Martinez et al., 2019; Menéndez \& Martinez, 2019). It shows that one of the most used methods is the total physical response, the same that is based on the coordination of speech and physical action this technique stimulates the motor system, since the child feels more using this type of methods where

$$
\begin{array}{r}
\text { Delgado, J. L. D., Bone, Y. I. E. B., Lascano, M. A. G. L., \& España, S. G. G. E. (2019). Dyslexia as learning } \\
\text { problem and its pedagogical intervention. International Journal of Health Sciences, 3(3), } 1-7 . \\
\text { https://doi.org/10.29332/ijhs.v3n3.333 }
\end{array}
$$


he does not You have to do no reading, this methodology will give greater result if it is used especially at a very young age.

In this way, the difficulty presented in your reading-writing persists, but it will help you to have a better knowledge of the lexicon, therefore, you will get better at identifying written words. In addition, the multisensory method can be used, which consists of entering the information at the same time in different ways, which can be auditory-visual, tactile and kinesthetic.

\subsection{Methodologies}

Learning is not only the one that occurs between the teachers - student, but rather to apply different ways to achieve it, making use of the different applications. it find today and serve to have a more interactive class, making the student become more innovative, reflective, in turn explore and apply educational applications in favor of improving their learning Rello (2013), suggests that one of the tools that will help improve the reading of people with dyslexia is computer science, where it has been scientifically demonstrated the aforementioned. Being able to modify the design and size of texts in computer applications, such as word processors that have different tools so that the student can use them, with the aim of improving the reading and writing process.

\section{Technologies applied to dyslexia}

The use of educational video games helps children detected with dyslexia problems, as it will help with the training of their specific skills, in addition they are directly linked to some real aspect, which favors the student, Marcano (2010), he says that these types of applications must be applied in order to improve learning in this condition today

There are a list, to games can has applied children with dyslexia. It considered as didactic, becoming a very important tool to motivate learning in turn to help children become more familiar with letters, words and sounds, Play (2016), mentions that, it has been shown that the child with this symptom is facilitated learning when sounds are used to relate the words.

With the use of video games, students improve their concentration and skills to help them make decisions more easily and quickly, achieving a better disbursement (Gutierrez, 2013), this type of learning becomes less complicated than the traditional one, making the student not realize that he has a disorder.

It is very important that the student feels recognized when using this type of applications; therefore, rewards should has used whenever their disbursement is better. Thus assessing all the effort that is made to acquire new knowledge, these types of techniques greatly favor students in their learning process, making knowledge better assimilated at each stage of teaching.

These types of disorders must has identified as quickly as possible, since in educational institutions due to lack of knowledge we find students in different educational levels (The Understood team, 2017). He states that, with this condition, if they are detected, making learning more difficult, that is why it is recommended that departments called DECE become more involved with the students.

Dyslexia is a condition that affects the child but it should has emphasized, that it is not a disability since it does not affect the motor part of the student. This type of conditions implies that educational institutions must encourage changes in all aspects to provide support to these children, since no child can be removed from their right to learn or to be part of an educational institution.

The research work is based on studies by different authors and specialists in the field,. The same as through various studies analyzes focused on children's disorders, their influence on learning. The different consequences it has on the teaching process In addition to providing the necessary tools to learn about these disorders, such as dealing with them by applying innovative methodologies, making special use of the new technologies that can has applied in the educational field, making the student have an educational environment very different from the traditional one.

It could show that teachers who apply technologies achieve better performance of students with dyslexia disorders as, in which the student learns by playing this methodology, can be applied without having students with disorders, which through this method can be obtained a better student performance achieving a significant learning that will in their memories without being forgotten. 
Finally, it can have indicated that educational disorders have been and will be part of the educational process. It is currently more evident to be able to recognize a student who has a disorder, dyslexia a silent disorder showing in the early stages of the students, where they can be evidenced with clarity and guide the student with the specialist staff. Dyslexia is one more condition, not a disease where the student has no problems in any of their physical abilities.

\section{Conclusion}

It is recommended to make academic reinforcements focusing on the area of language, specifically in reading and writing in order to include children who suffer from this anomaly in the different school activities, on the other hand the teacher is responsible for spreading confidence and security in them, highlighting their achievements and motivating them to move forward and seek to break the imposed barrier.

Finally, the teacher looks for different methodologies to be able to reach the student who presents this disorder since there is currently a wide variety of computer applications that facilitate the teaching-learning process, in turn a more dynamic class is achieved, the same one that is It is proven that it is the one that has the most accepted by the student and also focuses on practical learning that is where the student manages to learn more easily and in the case of children with dyslexia, their educational process will be facilitated

\section{Acknowledgments}

We thank the editor of IJHS for their valuable time, support and advice.

Delgado, J. L. D., Bone, Y. I. E. B., Lascano, M. A. G. L., \& España, S. G. G. E. (2019). Dyslexia as learning problem and its pedagogical intervention. International Journal of Health Sciences, 3(3), 1-7. 


\section{References}

Ana, M., Cristian, A., María, L., Carla, Y., \& José, A. (2017). Connectivism And Dyslexia. INFAD Journal of Psychology, 4(1), 253-259. https://doi.org/10.17060/ijodaep.2017.n1.v4.1054

Castejón, JL, \& Navas, L. (2011). Difficulties and disorders of learning and development in children and primary school. Alicante: University Club Editorial .

Cervantes, A., Roda, D., Tarazona, N., Rosello, S., \& Perez-Fidalgo, J. A. (2013). Current questions for the treatment of advanced gastric cancer. Cancer treatment reviews, 39(1), 60-67. https://doi.org/10.1016/j.ctrv.2012.09.007

Delgado, M. A. C., Delgado, R. I. Z., Palma, R. P., \& Moya, M. E. (2019). Dyscalculia and pedagogical intervention. International Research Journal of Management, IT and Social Sciences, 6(5), 95-100. https://doi.org/10.21744/irjmis.v6n5.710

Gutierrez, N., Kindratt, T. B., Pagels, P., Foster, B., \& Gimpel, N. E. (2014). Health literacy, health information seeking behaviors and internet use among patients attending a private and public clinic in the same geographic area. Journal of community health, 39(1), 83-89. https://doi.org/10.1007/s10900-013-97425

Malaga, M. (2014). The European Patent with Unitary Effect: Incentive to Dominate?. IIC-International Review of Intellectual Property and Competition Law, 45(6), 621-647. https://doi.org/10.1007/s40319-0140237-4

Marcano, D. C., Kosynkin, D. V., Berlin, J. M., Sinitskii, A., Sun, Z., Slesarev, A., ... \& Tour, J. M. (2010). Improved synthesis of graphene oxide. ACS nano, 4(8), 4806-4814. https://doi.org/10.1021/nn1006368

Martinez, C. J. B., Vasquez, B. S. G., Martinez, M. E. M., \& Gámez, M. R. (2019). Learning problems on educational context for cascol parish. International Journal of Social Sciences and Humanities,3(2), 145-155. https://doi.org/10.29332/ijssh.v3n2.306

Menéndez, E. S., \& Martinez, M. E. M. (2019). Problems of learning and pedagogical intervention. International Journal of Social Sciences and Humanities, 3(2), 105-111. https://doi.org/10.29332/ijssh.v3n2.301

Ortiz, M. S., \& Shelton IV, F. E. (2016). U.S. Patent No. 9,402,626. Washington, DC: U.S. Patent and Trademark Office.

Pennington, K. A., Schlitt, J. M., Jackson, D. L., Schulz, L. C., \& Schust, D. J. (2012). Preeclampsia: multiple approaches for a multifactorial disease. Disease models \& mechanisms, 5(1), 9-18. https://doi.org/10.1021/10.1242/dmm.008516

Play, G. (2016). https://play.google.com/store/apps/details?id=ar.com.gitmo.sanapalabras\&hl=en

Rello, L., \& Baeza-Yates, R. (2013, October). Good fonts for dyslexia. In Proceedings of the 15th international ACM SIGACCESS conference on computers and accessibility (p. 14). ACM.

The Understood team. (2017). Dyslexia: What is and what is not. https://www.understood.org/es$\mathrm{mx} /$ learning-attention-issues/child-learning-disabilities/dyslexia/dyslexia-what-it-is-and-isnt

Vasquez, J. M. C., Quiroz, P. M. Z., \& Martinez, M. E. M. (2019). Dyslexia: ways to identify and address it. International Research Journal of Engineering, IT \& Scientific Research, 5(4), 68-74. https://doi.org/10.21744/irjeis.v5n4.717 


\section{Biography of Authors}

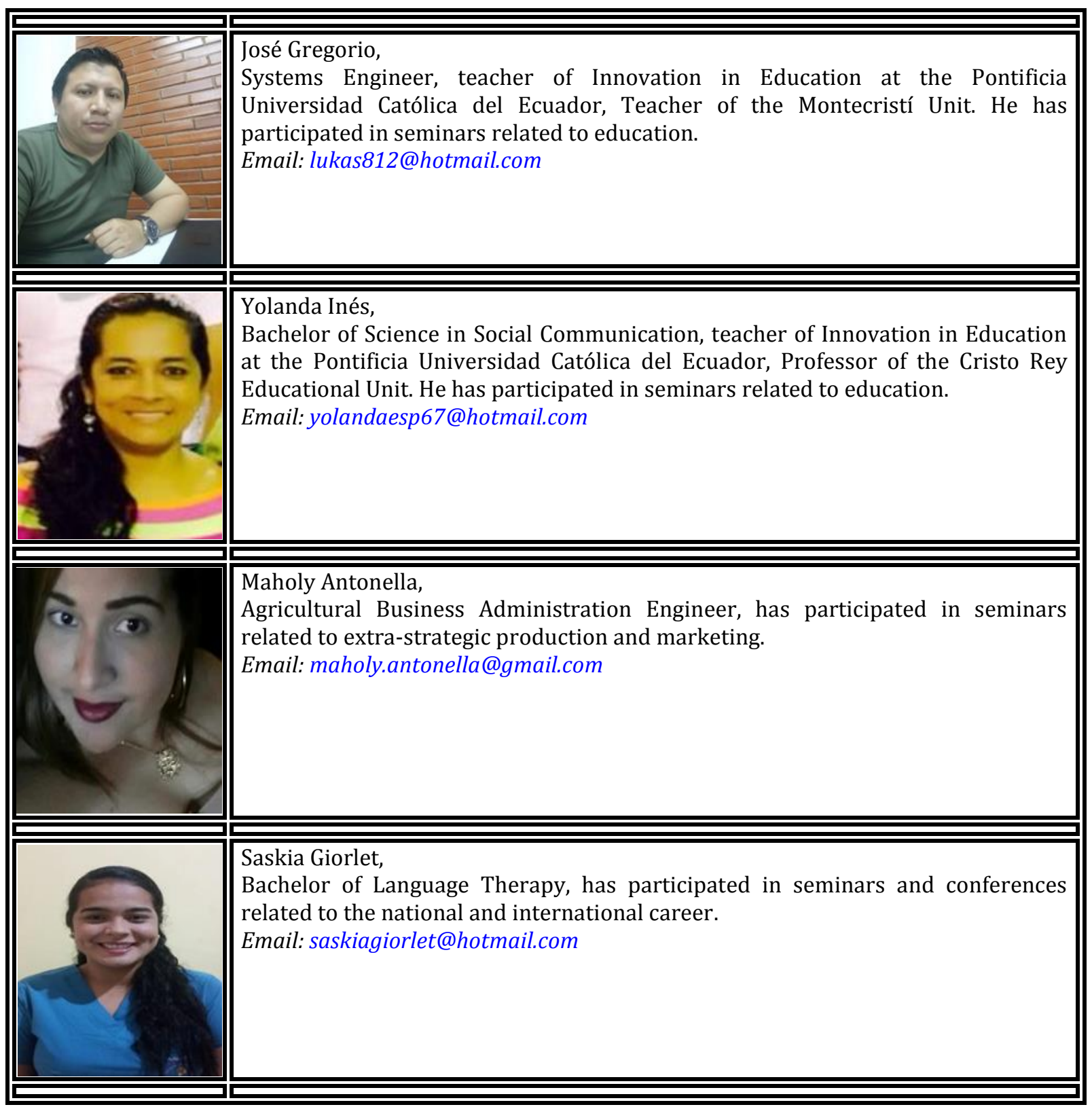

Delgado, J. L. D., Bone, Y. I. E. B., Lascano, M. A. G. L., \& España, S. G. G. E. (2019). Dyslexia as learning problem and its pedagogical intervention. International Journal of Health Sciences, 3(3), 1-7. https://doi.org/10.29332/ijhs.v3n3.333 